\title{
Study on Engineering Change Management in the Supply Chain of Aerospace Valves Realization
}

\author{
Steny Ann Sabu \\ M.Tech Industrial Engg. \& Mgmt Student \\ Dept. of Mechanical Engineering \\ RIT - Govt. Engineering College \\ Kottayam, 686501
}

\author{
Arunprakash N V S \\ Project External Guide, Scientist \\ Control Systems \& Components Entity \\ Liquid Propulsion Systems Centre, \\ ISRO,Trivandrum, 695547
}

\author{
Dr. Ciby Thomas \\ Project Internal Guide, Professor \\ Dept. of Mechanical Engineering \\ RIT - Govt. Engineering College \\ Kottayam, 686501
}

\begin{abstract}
Realization of aerospace valves involves various process viz. conceptualization, design, manufacturing, inspection, procurement, assembly \& testing. Aerospace valves are configured with static and dynamic parts. Each part consists of many configuration items. Changes required, in any of the Configuration Items (CI) viz. Drawing, Process, Procedure, Specification \& Material needs to be assessed in real time for maintaining a healthy supply chain, as processes are carried out both internally \& externally. Engineering change affects the production efficiency and the stability of a production system. Managing the configuration items throughout the valves life cycle vide paper based is highly complex. To overcome the cited difficulties, software based engineering change management methodology was conceived. This includes a feature for identifying the impact of engineering change on the product life cycle. To identify the dependencies among CI's, a framework with unified CI code for drawings was conceived. Survey was conducted among various stakeholders to finalize the overall scope of framework \& relevance. The stakeholder responsibilities were depicted in a Responsibility Assignment Matrix (RACI). The dependencies among part drawing and assembly drawings CIs were linked with Valve drawing CIs vide Design Structure Matrix (DSM). This helped in integrating the existing inventory management software, which is already in operation and the proposed configuration management software. This is an indigenous effort.
\end{abstract}

Keywords-Engineering Change Management; Configuration Management; DSM; Product Data Management; Aerospace Industry

\section{INTRODUCTION}

Engineering Changes are highly indispensable for any supply chain, which is appropriate for aerospace valves realization. Addition, removal or modification on any of the bill of materials, specifications, documents, materials and drawings can be generally termed as an engineering change. Industries are facing more difficulties due to the engineering change that shall occur in any of the supply chain processes like design, production, assembly \& testing and so on. Each change has subsequent functional as well as technical impact on other realization processes, which further impacts the cost, schedule and quality. Hence, it is highly relevant to carry out an impact analysis in real time as this can maintain the production efficiency to a greater extent. Engineering Change Management (ECM) plays a pertinent role in this aspect, as it shall effectively manages the changes in a well defined systematic approach.

The valves are realized using fabricated parts as well as standard parts, through well defined processes and procedures. Fabricated parts are realized through external industries and standard parts are procured from the qualified sources. Both parts consist of various configuration items (CI). Changes in these configuration items must be efficiently managed by an Engineering Change Management for maintaining a healthy supply chain. During the study, it was observed that, the Engineering Change Management processes are handled manually, which consumes lot of paper work and found to be more tedious. Henceforth, an effectively functioning fully automated ECM is a necessity for sustaining a stabilized manufacturing system. SWOT Analysis and the Questionnaire survey among various stakeholders of ECM further strengthened the scope and relevance of this study.

In this scenario, a software framework with unified CI code for drawings was developed. Well defined Responsibility Assignment Matrix supporting the framework, identifying the roles and responsibilities for every stakeholder was generated. Categorization of change and its dependencies with each CI was conceptualized through Design Structure Matrix. The current study focused only with the framework development of drawing CI and automated ECM. In future course of action, activities pertaining to other CIs can be attained.

\section{ENGINEERING CHANGE MANAGEMENT}

Engineering Change Management is the process of managing all the changes related to activities like change request, change verification, change approval, change release and so on. As the study entity currently handles ECM manually, it consumes lengthy cycle time and more paper works involved; hence, an ECM framework through software was developed. 

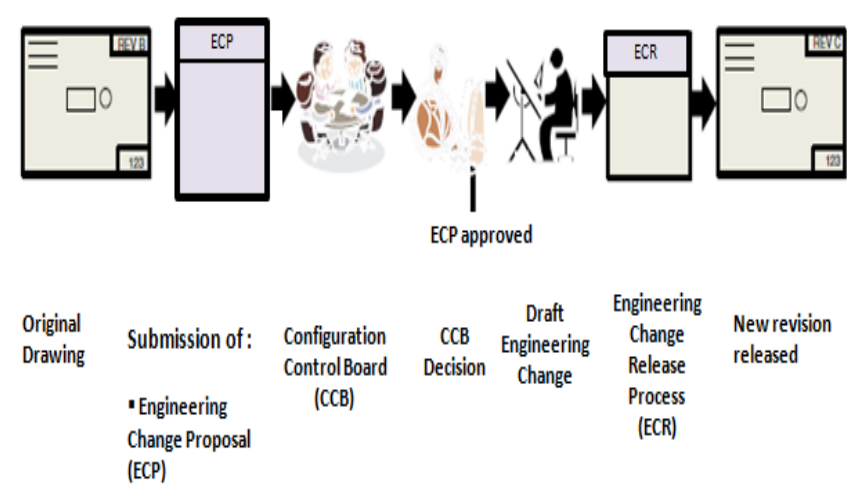

Fig. 1 : Workflow of manually handling Engineering Change Management

\section{CONFIGURATION MANAGEMENT}

Engineering Change Management is a subset of Configuration Management. As per MIL-HDBK-61A(SE), Configuration Management is defined as a management process for establishing and maintaining consistency of a product's performance, functional, and physical attributes with its requirements, design and operational information throughout its life. The key activities of CM are Configuration Identification, Configuration Control, Configuration Status Accounting and Configuration Auditing. CM is an inevitable tool throughout the life cycle of a product. The integrity and continuity of the design, engineering trade off decisions made between technical performance, productivity and so on are recorded, communicated and controlled by means of proper configuration management.

\section{A. Configuration Identification}

The Configuration Identification is the process of identifying the product architecture and the selection of configuration items. Configuration Items are the fundamental building blocks of an ECM process. Here, the CIs and its sub effected parts are captured through a Fish Bone Diagram. The major CIs identified in this study are Drawing, Specification, Material, Process Document and Procedure Document.

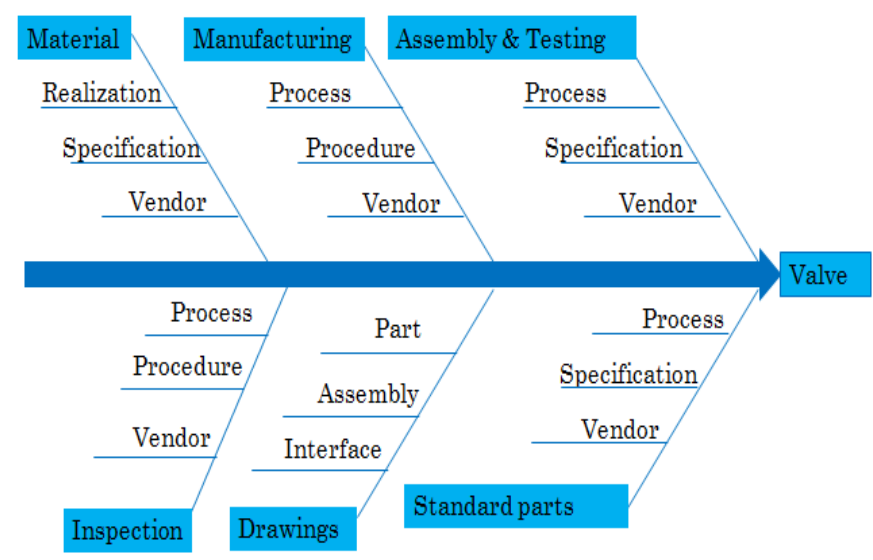

Fig. 2 : Fish Bone Diagram of CIs

\section{B. Configuration Control}

The Configuration Control (CC) plays a very important role in the development, continuity in performance of valves designed and realized to achieve set of specifications. CC is a systematic process which ensures that changes to released configuration documentation are properly identified, documented, evaluated for impact, approved by an appropriate level of authority, incorporated and verified. $\mathrm{CC}$ activities are performed by a review committee known as Configuration Control Board. A board composed of technical and administrative representatives, recommends approval or disapproval of proposed engineering changes from a CI's current baseline. Here CCB consists of a CC Engineer, Designer, Production Agency, Inventory Agency, Assembly Agency, Inspection Agency, Quality Assurance, and concerned Project Representative.

\section{Configuration Status Accounting}

The configuration management activity concerns capture and storage of, and access to, configuration information needed to manage products and product information effectively [4].

\section{Configuration Auditing}

Configuration Auditing is the process to verify that the configuration management system is efficiently functioning or not.

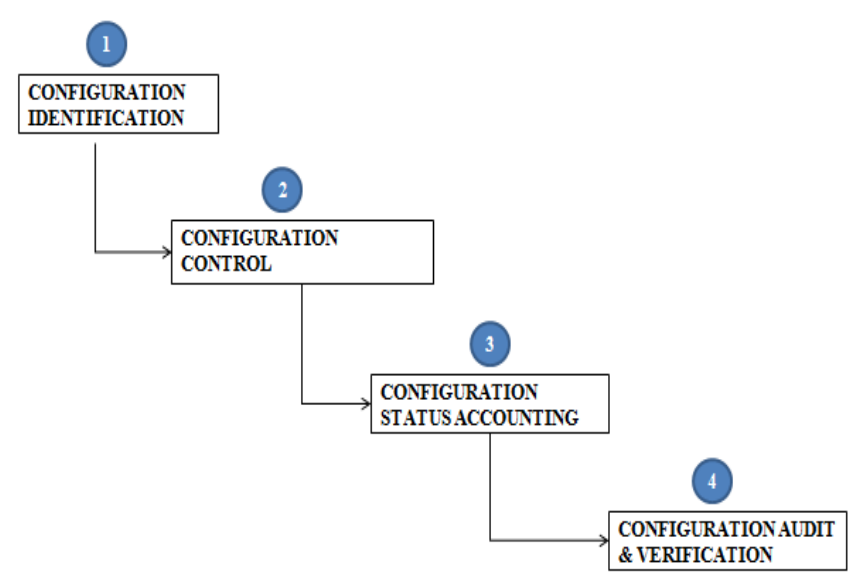

Fig. 3 : Generic Activity Diagram of Configuration Management (CM)

An engineering change proposal (ECP) is the management tool used to propose a configuration change to a configuration item (CI), system's baseline performance requirements and configuration documentation established during design $\&$ development of the system.

\section{CHALLENGES IN MANUALLY HANDLING ECM}

In this study, SWOT analysis as well as Questionnaire Survey was conducted among various stakeholders of ECM.

\section{A. SWOT Analysis}

SWOT analysis on manually functioning ECM process was carried out. The major strengths are adopting standard guidelines, established ECM procedure and dedicated team work for ECM. Weaknesses are more time for completion of Engineering Change Order w.r.to drawings, lack of accessibility for concerned stakeholders about product configuration and graphical visibility of EC proposal and its impact in life cycle. Opportunities are software oriented approach, functional expansion for documents, materials and specifications other than drawings. Threats are cyber crimes and manual operational error. 


\section{B. Questionnaire Survey}

Questionnaire Survey was carried out among various ECM stakeholders like Configuration Control Board, Design Team, Manufacturing Team, Assembly \& Testing Team, Quality Control and Quality Assurance. The questions were prepared as per the DMAIC approach - Define, Measure, Analysis, Implement and Control. The survey synopsizes that 75 to $80 \%$ of stakeholders recommended for a fully automated ECM through software rather than using a manual one. $20 \%$ of the respondents suggested that the data extraction is difficult. system was recommended by $50 \%$.

\section{METHODOLOGY FOR SOFTWARE BASED HANDLING OF ECM}

As the study entity is gearing up to scale up industry participation to meet Indian space programme demands, the entire process of ECM related to valves needs to be established in software mode, for effective configuration management throughout life cycle. The merit of ECM through software will reduce engineering change order cycle time, reduce errors, delays, scrap and rework.

\section{A. Framework for automated ECM workflow for drawing}

A framework was prepared based on a questionnaire survey conducted with concerned stakeholders involved in the supply chain. In the proposed web interface framework, each stakeholder will be intimated about the engineering change prior to $\mathrm{CCB}$ discussion, for better assessment and submission with comments. Framework was conceived in three different milestones.

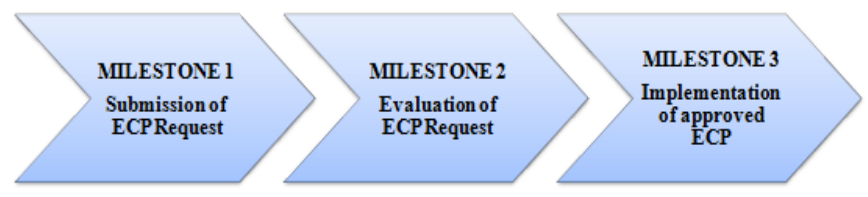

Fig. 4 : Framework for automated ECM Workflow

Milestone 1 is the submission of engineering change proposal (ECP) request by the originator and this workflow consists of categorization of change, impact analysis and verification of change request by Quality Assurance, Production Agency and Assembly Agency.

Milestone 2 is the ECP evaluation process which includes sub activities like pre - CCB meeting requirements, CCB meeting decisions and post - CCB meeting actions.

Milestone 3 is the implementation of approved engineering changes. In this milestone, hardcopy drawing verification, negative drawing verification and amendment sheet verification among various stakeholders will be carried out followed by change control auditing system.
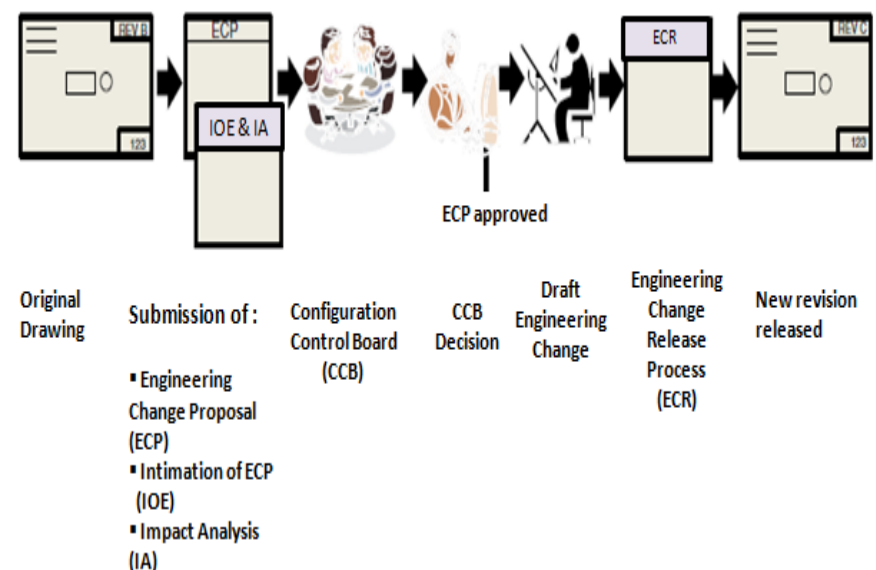

Fig. 5: Workflow of Engineering Change Management through software

\section{B. Categorization of Changes}

Changes were categorized bit deeper for the successful functioning of automated ECM process. The changes were primarily classified as per the configuration item. In drawing, changes are further classified into the changes that belong to the type of drawings involved like changes in fabricated part drawing, standard part drawing, assembly drawing, sub assembly drawing and interface drawing. And among each part drawing, the changes are further categorized as Engineering changes and Ad-hoc changes.

Engineering changes are the changes that have functional impact on other supply chain phases. This can be of dimensional changes, changes in geometrical tolerances, material changes, surface treatment, spring specification and so on

Whereas, Ad-hoc changes are the changes which do not have functional impact on any of the supply chain stages. The major categorized ad-hoc changes are addition, removal or modification in tabular details, engravings and so on.

\section{Responsibility Assignment Matrix - RACI}

The stakeholder roles and responsibilities were specifically depicted in a RACI Matrix. In 'RACI', R stands for Responsible- the one who executes the activity and gets the job done, A stands for Accountable - the one who owns the quality and end result, $\mathrm{C}$ stands for Consulted - the one who others can get consulted for opinion and capturing knowledge and I for Informed - the one who needs to kept up to date and the one need information about process execution. Stakeholder identities were listed in the columns and the tasks involved in each milestone were listed in the rows.

\section{Design Structure Matrix - DSM}

The categorization of changes and its dependency with each configuration item was captured in a Design Structure Matrix. The categories and sub categories lists were obtained through a unified CI code as a tree structure. Unified codes for drawing CIs were generated with a prerequisite of linking the proposed configuration management software and existing inventory management software, which is already operational. This is an indigenous effort. 


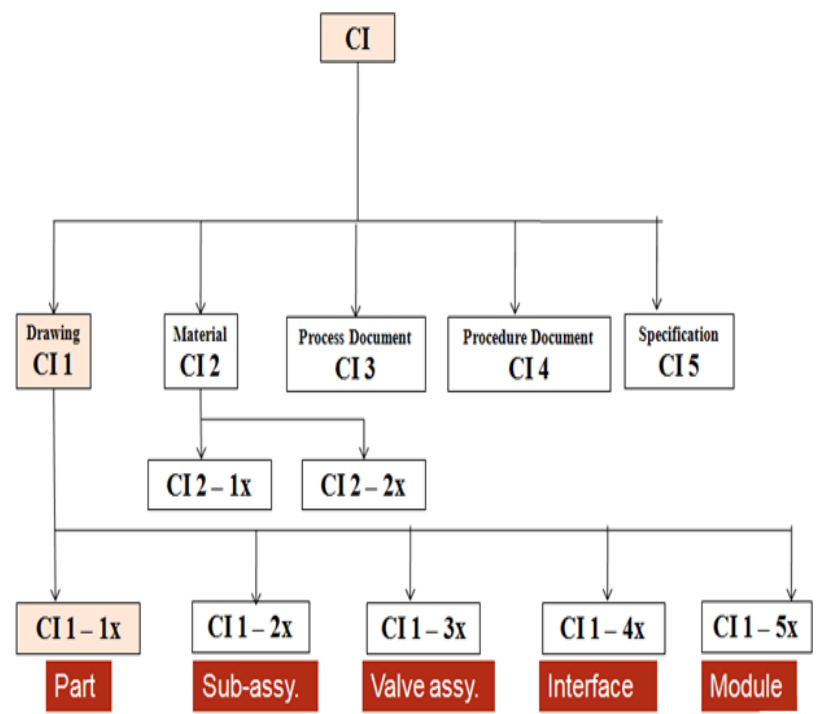

Fig. 6: Tree Structure of unified CI codes

\section{CONCLUSION}

The study revealed that the existing manually handling ECM is agreeable during development and minimal production phase. As the entity is planning to increase the number of projects in the upcoming years, the relevance of an automated ECM process is very high. In this study, a framework for a software-based ECM workflow for drawing CI was captured; in a way that it makes a paper free process. Thereby, it reduces the cycle time, enhances traceability of changes and the change history throughout the life cycle and so on. Automated ECM for CIs other than drawings shall be considered as a future scope of work. Thus, a fully automated ECM vide software can help the supply chain of aerospace valve realization effectively and efficiently.

\section{ACKNOWLEDGMENT}

We express our sincere gratitude towards the Configuration Management team in Control Systems \& Components Entity and associated stakeholders of Liquid Propulsion Systems Centre, ISRO for granting us the permit to do the study.

\section{REFERENCES}

[1] Natalia Iakymenko, Anita Romsdal, Marco Semini, Jan Ola Strandhagen 2018. Managing engineering changes in the engineer-toorder environment: challenges and research needs. International Federation of Automatic Control, Vol.51, pp.144-151, 2018

[2] I C Wright., "A review of research into engineering change management: implications for product design", Design Studies, Vol.18, pp.33-42, 1997

[3] GüntherSchuha, Michael Riesenera, Christian Tönnesa, SasaAleksic., "Technical change management for the maintenance of product platforms", CIRP Design Conference, Vol.60, pp.458 - 463, 2017

[4] MIL-HDBK-61A(SE) - MILITARY HANDBOOK for Configuration Management Guidance, 2001

[5] NASA - STD - 0005 : NASA CONFIGURATION MANAGEMENT (CM) STANDARD, 2015 